\title{
Factors Associated with Elective Withdrawal of Maintenance Hemodialysis: A Case-Control Analysis
}

\author{
James B. Wetmore ${ }^{a, b}$ Heng Yan ${ }^{a}$ David T. Gilbertson ${ }^{a}$ Jiannong Liu ${ }^{a}$ \\ ${ }^{a}$ Chronic Disease Research Group, Minneapolis Medical Research Foundation, Minneapolis, MN, USA; ${ }^{b}$ Division of \\ Nephrology, Hennepin County Medical Center, University of Minnesota, Minneapolis, MN, USA
}

\section{Keywords}

Dialysis · Elective dialysis withdrawal · End-of-life care

\begin{abstract}
Background: Associations of demographic factors with elective dialysis withdrawal and setting of death, patterns of illness trajectories preceding death, and how illness trajectories, particularly worsening putative disability, are associated with elective withdrawal are poorly understood.Methods: Using United States Renal Data System data, we performed a case-control analysis of hemodialysis patients who died in 2010-2015. A disability proxy score characterized disability; logistic regression identified characteristics associated with death from withdrawal and with death setting; and groupbased trajectory models characterized the trajectory of disability in the months preceding death. Results: We identified 14,571 (9.2\%) patients who withdrew and 144,305 (90.8\%) who died of a non-withdrawal cause. Women were more likely than men to withdraw (OR 1.19, 95\% CI 1.15-1.24). The most rural patients were more likely to withdraw than the most urban (OR 1.37, 95\% Cl 1.25-1.50). Medicaid coverage (a marker for impoverishment) was associated with less withdrawal (OR 0.90, 95\% Cl 0.86-0.94). Disability proxy score was strongly related to withdrawal: the OR for patients in the highest score category was 31.16 (95\% Cl 28.40-34.20) versus those with a score of 0 . Women and whites (vs. blacks)
\end{abstract}

were overrepresented in the worst, versus better, proxy disability score trajectory. In-hospital death and death in the intensive care unit were more common in women and minorities than in men and whites, but less common in the most rural patients. Conclusions: Important differences separate patients who electively withdraw from those who die of non-withdrawal causes. Worsening disability, in particular, may be a marker for withdrawal.

(c) 2020 S. Karger AG, Basel

\section{Introduction}

Conservative care for patients with advanced kidney disease [1-5], palliative care in nephrology [6-11], and withdrawal from dialysis [12-19] are topics of increasing interest. Elective dialysis withdrawal is an important care option because it permits patients to exert agency over the timing and setting of death [20-24]. We [25] and others $[13,14,19,26,27]$ have examined factors associated with dialysis withdrawal. However, most studies use data assessed primarily at the time of dialysis initiation, an approach that may not fully reflect worsening health status and increasing physical dependency preceding death. The Renal Physicians Association's shared decision-making guidelines for dialysis initiation and withdrawal recognize the importance of intercurrent events on the as-

\section{KARGER}

(c) 2020 S. Karger AG, Basel

karger@karger.com

www.karger.com/ajn
James B. Wetmore, MD, MS

Chronic Disease Research Group

Hennepin Healthcare Research Institute

701 Park Avenue, Suite S4.100, Minneapolis, MN 55415 (USA)

E-Mail James.Wetmore@ hcmed.org 
sessment of treatment goals [20], suggesting that a patient's clinical course is relevant to discussions about elective withdrawal.

Elective dialysis withdrawal is an important care option for patients with poor health status. Many patients may choose elective withdrawal if they and their physicians had a better understanding of how illness unfolds prior to death (a phenomenon that we term the "illness trajectory") and how, in particular, worsening disability may herald death. Previously, we examined factors associated with elective withdrawal by contrasting withdrawers with dialysis patients who remained alive [25]. In doing so, we used an administrative claims-based score that serves as a marker of putative disability to determine how worsening disability might be associated with cause of death. However, whether our findings applied specifically to patients who electively withdrew, as opposed to those who died of other causes, remained uncertain. We therefore examined the association of demographic and socioeconomic factors with cause of death (withdrawal vs. non-withdrawal) and with the setting of death. We also examined patterns of illness trajectories prior to death and how such trajectories, particularly putative disability, were associated with elective dialysis withdrawal. We hypothesized that disability, rather than acute medical events per se, would be associated with elective dialysis withdrawal.

\section{Materials and Methods}

Data Sources, Study Sample Creation, and Study Design

We performed a case-control analysis of prevalent Medicarecovered patients receiving maintenance hemodialysis using the United States Renal Data System (USRDS) end-stage renal disease (ESRD) database, a US government-funded registry of nearly all patients receiving maintenance dialysis in the US. It consists of data from the ESRD Medical Evidence Report (Centers for Medicare and Medicaid Services [CMS] form CMS-2728), the ESRD Death Notification (form CMS-2746), and Medicare Parts A and B claims. Because our intention was to study prevalent hemodialysis patients and because we recently examined elective dialysis withdrawal in new (duration $<1$ year) initiates [28], we focused on patients who had survived for $\geq 1$ year before dying between January 1, 2010, and September 30, 2015. The latter date was chosen because (i) 2015 data were the most recent available at the time the study commenced and (ii) we wanted to avoid complexities associated with transition from International Classification of Diseases-9 to -10, which occurred in October 2015 in the US. After identifying patients who had died, we looked back 6 months preceding death to determine patterns of medical events, hospitalizations and skilled nursing facility (SNF) stays, and a novel disability proxy score (described below) to create a picture of medical status preceding death. We selected a 6-month period because examination of the data pat- terns suggested that little changed between withdrawers and those who died of a non-withdrawal cause between 12 and 6 months prior to death; in contrast, patterns distinguishing withdrawers from those who died of a non-withdrawal cause began to become more evident in the 6 months prior to death.

\section{Determination of Withdrawal}

The definition of dialysis withdrawal was carefully considered. The key source was the US ESRD Death Notification form. We sought to avoid misclassifying cessation of dialysis immediately prior to imminent death as withdrawal. We established primary and, for the purposes of a sensitivity analysis, secondary definitions of withdrawal. Full details are described in the online supplementary Methods (for all online suppl. material, see www.karger. com/doi/10.1159/000505993).

\section{Medical Events and Functional Status}

Medical events included hospitalizations for the indications listed in online supplementary Table S1. To create a disability proxy score, we employed a variation of a previously developed claims-based algorithm based in part on durable medical equipment (DME) use. This score has not been validated, although it has been used in previous studies [25, 29]. A complete description of the score, in which a higher number represents worse disability, appears in the online supplementary Methods and Table S2.

\section{Demographic and Comorbidity Variables}

Other variables used for modeling were demographics, primary cause of ESRD, dialysis duration, days of institutional stay (over the previous 6 months), degree of urbanicity, Medicaid coverage (a marker of impoverishment), and comorbid conditions (over the previous 12 months). Degree of urbanicity, a proxy for distance between the home and locations of health-care delivery, was classified into 4 groups using Rural Urban Commuting Area codes. Comorbid conditions were ascertained by the presence of one or more inpatient or 2 or more outpatient/Part B claims 30 days apart.

\section{Statistical Analysis}

We used descriptive statistics (count $[n]$, percentage [\%]) where appropriate, and, for dialysis duration and institutionalized days, median (interquartile range). Missing data were rare; when data were missing, a separate category was created. For each month, medical event rates were calculated as number of events in the month per 100 days; lengths of hospitalization and of SNF stays were calculated likewise. Given the nature of DME (specifically, as a "durable good"), the mean monthly disability proxy score was calculated using data from a rolling 3-month window. (In other words, the proxy disability score generated 6 months before death required us to ascertain relevant claims from pre-DME claims accumulated over the previous 3 months.) Rates were plotted over time as death approached. A logistic regression model was then created to identify characteristics associated with death from withdrawal versus death from a non-withdrawal cause.

To determine the trajectories of the patterns of medical events, hospitalizations and SNF stays, and putative disability in the months prior to death (withdrawal and non-withdrawal), we used group-based trajectory models, which identify clusters of individuals following similar progressions over time [30-32]. We used the SAS procedure Proc TRAJ [33], combining patients who did and did not withdraw into one risk set and then determining, via a lo- 
gistic model, how withdrawers (vs. non-withdrawers) were more likely to follow one trajectory versus another. More detail is provided in the online supplementary Methods.

Finally, we assessed setting of death, as described in the online supplementary Methods.

\section{Results}

\section{Characteristics of the Study Sample}

Of 463,813 deaths in 2010-2015 identified in the Death Notification file, 183,483 patients aged $\geq 18$ years with at least 1 year of dialysis before death and sufficient Medicare coverage were identified (online suppl. Fig. S1). Of these, 14,571 met our definition of withdrawal and 144,305 died of non-withdrawal causes (totaling 158,876); 24,607 died of causes that could not readily be determined. Thus, $9.2 \%$ of patients with known cause of death withdrew and $90.8 \%$ died of a non-withdrawal cause.

Patients who withdrew were generally older and more likely to be female, of white race, and from a rural setting (Table 1). Withdrawers were less likely to have Medicaid coverage. Comorbidity levels were generally comparable. Withdrawers had substantially worse disability proxy scores: only $3.9 \%$ had a score of 0 , versus $21.9 \%$ of those who died of non-withdrawal causes; $76.5 \%$ of withdrawers had a score of 7 or higher, versus $15.9 \%$ of others.

\section{Factors Associated with Withdrawal as a Cause of \\ Death}

The comparison of factors associated with withdrawal, versus death from other causes, is shown in Table 2. Older age was associated with withdrawal; adjusted odds were 2.41-fold (95\% CI 2.26-2.59) higher for patients aged $\geq 85$ years than for those aged $45-64$ years. Women were more likely than men to withdraw than to die of another cause (OR 1.19, 95\% CI 1.15-1.24). Except for Native Americans, odds of withdrawal were generally lower for non-white patients, compared with white patients: ORs were 0.42 (95\% CI 0.40-0.45) for black, 0.61 (95\% CI $0.53-0.70)$ for Asian, and 0.66 (95\% CI 0.62-0.71) for Hispanic patients. Increasing rurality was associated with increased likelihood of withdrawal: the OR for patients in isolated rural towns, compared with urban centers, was 1.37 (95\% CI 1.25-1.50). Medicaid coverage was associated with decreased likelihood of withdrawal (OR 0.90, $95 \%$ CI $0.86-0.94)$. The disability proxy score was associated with withdrawal in graded fashion: compared with patients with a score of 0, ORs were 1.68 (95\% CI 1.51-
1.87) for those with a score of $1-2,2.68$ (95\% CI 2.39 3.01) for score 5-6, and 31.16 (95\% CI 28.40-34.20) for score 7 or higher.

\section{Rates of Events and Health-Care Encounters before Death}

Rates of medical events increased roughly 2 - to 8 -fold over the 6 months before death for withdrawers and for patients who died of non-withdrawal causes, but the increase appeared to be more pronounced for the latter group. Rates of myocardial infarction and sepsis appeared to increase in the 2 months preceding death for all patients, but less sharply for withdrawers (Fig. 1a), and this appeared to be the case for any medical event and for major medical events (Fig. 1b). Hospitalization rates differed little between withdrawers and patients who died of nonwithdrawal causes, but rates of SNF stays were persistently higher for withdrawers (Fig. 1c).

The pattern for the disability proxy score, however, appeared to differ from the other patterns. Scores gradually increased (worsened) for both groups over time, but appeared to be persistently higher for those who eventually withdrew. Scores then became substantially higher for withdrawers, compared with those who otherwise died, as death approached (Fig. 1d).

\section{Illness Trajectories before Death}

Illness trajectories are shown in online supplementary Figure S2. For any medical events (online suppl. Fig. S2a), we noted 2 major trajectories, one characterized by a persistently higher burden of events/illness but a less pronounced increase immediately prior to death, and the other by a generally lower burden of events/illness but a more pronounced increase in the months immediately prior to death. The percentage of patients who died of withdrawal did not differ between the trajectories (trajectory 1 , the "healthier trajectory," 9.1\%; trajectory 2, the "sicker trajectory," 9.3\%; $p=0.21$ ).

In contrast, for the disability proxy score (online suppl. Fig. S2b), the group with persistently higher scores over time appeared to experience the more pronounced increase prior to death. Significantly more patients who died of withdrawal were on trajectory 2 ("sicker," 20.4\%) than were on trajectory 1 ("healthier," $5.1 \%$ ), $p<0.0001$.

Factors associated with specific trajectory ("sicker" vs. "healthier") were modeled for the disability proxy score and for acute medical events. For the disability proxy score, women tended to be more likely to experience the "sicker" trajectory 2 (Table 3), OR 1.32 (95\% CI 1.291.35). Compared with whites, members of racial minority 
Table 1. Baseline characteristics of the study sample

\begin{tabular}{|c|c|c|c|}
\hline Characteristics & All & Death from withdrawal & Death from other cause \\
\hline Overall & 158,876 & 14,571 & 144,305 \\
\hline Age, years, mean (SD) & $69.4(13.0)$ & $75.7(11.4)$ & $68.8(13.0)$ \\
\hline \multicolumn{4}{|l|}{ Age, years } \\
\hline $18-44$ & $4.2(6,746)$ & $1.2(180)$ & $4.6(6,566)$ \\
\hline $45-64$ & $30.7(48,747)$ & $16.0(2,325)$ & $32.2(46,422)$ \\
\hline $65-74$ & $28.4(45,182)$ & $25.5(3,712)$ & $28.7(41,470)$ \\
\hline \multicolumn{4}{|l|}{ Gender } \\
\hline Female & $44.4(70,533)$ & $49.0(7,139)$ & $43.9(63,394)$ \\
\hline Male & $55.6(88,343)$ & $51.0(7,432)$ & $56.1(80,911)$ \\
\hline \multicolumn{4}{|l|}{ Race/ethnicity } \\
\hline White & $48.2(76,605)$ & $68.3(9,957)$ & $46.2(66,648)$ \\
\hline Hispanic & $13.9(22,072)$ & $10.8(1,570)$ & $14.2(20,502)$ \\
\hline Dialysis duration, years, mean (SD) & $4.4(2.6 \pm 6.9)$ & $4.1(2.4 \pm 6.4)$ & $4.4(2.6 \pm 3.9)$ \\
\hline \multicolumn{4}{|l|}{ Dialysis duration, years } \\
\hline$<2$ & $16.6(26,318)$ & $18.0(2,629)$ & $16.4(23,689)$ \\
\hline $2-<5$ & $41.1(65,269)$ & $43.3(6,303)$ & $40.9(58,966)$ \\
\hline$\geq 5$ & $42.4(67,289)$ & $38.7(5,639)$ & $42.7(61,650)$ \\
\hline \multicolumn{4}{|l|}{ Primary cause of ESRD } \\
\hline Diabetes & $52.4(83,224)$ & $46.9(6,828)$ & $52.9(76,396)$ \\
\hline Hypertension & $29.1(46,283)$ & $31.0(4,517)$ & $28.9(41,766)$ \\
\hline Glomerulonephritis & $6.4(10,127)$ & $6.8(996)$ & $6.3(9,131)$ \\
\hline Other cause & $12.1(19,242)$ & $15.3(2,230)$ & $11.8(17,012)$ \\
\hline Institutional stay, days, median (IQR) & $19(5-53)$ & $28(9-65)$ & $18(5-52)$ \\
\hline Large rural city/town & $11.1(17,561)$ & $12.9(1,874)$ & $10.9(15,687)$ \\
\hline Small rural town & $6.2(9,857)$ & $7.0(1,022)$ & $6.1(8,835)$ \\
\hline Isolated small rural town & $4.3(6,827)$ & $5.5(808)$ & $4.2(6,019)$ \\
\hline Missing & $1.6(2,596)$ & $0.7(100)$ & $1.7(2,496)$ \\
\hline \multicolumn{4}{|l|}{ Medicaid coverage* } \\
\hline No & $53.6(85,106)$ & $64.6(9,413)$ & $52.5(75,693)$ \\
\hline Yes & $46.4(73,770)$ & $35.4(5,158)$ & $47.5(68,612)$ \\
\hline \multicolumn{4}{|l|}{ Comorbid conditions } \\
\hline ASHD & $56.6(89,868)$ & $57.9(8,435)$ & $56.4(81,433)$ \\
\hline $\mathrm{CHF}$ & $62.4(99,155)$ & $60.9(8,876)$ & $62.6(90,279)$ \\
\hline CVA/TIA & $21.7(34,526)$ & $25.7(3,750)$ & $21.3(30,776)$ \\
\hline PVD & $46.4(73,731)$ & $47.9(6,975)$ & $46.3(66,756)$ \\
\hline Other cardiac disease & $33.0(52,494)$ & $32.5(4,741)$ & $33.1(47,753)$ \\
\hline COPD & $36.0(57,205)$ & $35.4(5,162)$ & $36.1(52,043)$ \\
\hline GI bleeding & $12.5(19,912)$ & $13.4(1,952)$ & $12.4(17,960)$ \\
\hline Liver disease & $9.5(15,023)$ & $9.1(1,332)$ & $9.5(13,691)$ \\
\hline Dysrhythmia & $46.2(73,417)$ & $51.0(7,429)$ & $45.7(65,988)$ \\
\hline Cancer & $10.6(16,782)$ & $14.8(2,153)$ & $10.1(14,629)$ \\
\hline Diabetes & $72.4(114,991)$ & $67.0(9,766)$ & $72.9(105,225)$ \\
\hline
\end{tabular}


Table 1. (continued)

\begin{tabular}{lccc}
\hline Characteristics & All & Death from withdrawal & Death from other cause \\
\hline Liu comorbidity index & & & $5.3(7,619)$ \\
$\quad 0$ & $5.2(8,268)$ & $4.5(649)$ & $22.9(32,995)$ \\
$1-4$ & $22.7(36,047)$ & $20.9(3,052)$ & $21.0(30,272)$ \\
$5-7$ & $21.0(33,409)$ & $21.5(3,137)$ & $50.9(73,419)$ \\
$\geq 8$ & $51.1(81,152)$ & $53.1(7,733)$ & $21.9(31,631)$ \\
Disability proxy score & & $3.9(575)$ & $24.1(34,787)$ \\
$\leq 0$ & $20.3(32,206)$ & $6.6(959)$ & $24.0(34,598)$ \\
$1-2$ & $22.5(35,746)$ & $7.5(1,089)$ & $14.1(20,275)$ \\
$3-4$ & $22.5(35,687)$ & $5.5(796)$ & $15.9(23,014)$ \\
$5-6$ & $13.3(21,071)$ & $76.5(11,152)$ & \\
$\geq 7$ & $21.5(34,166)$ & & \\
\hline
\end{tabular}

Values are $\%(n)$ except as indicated.

* Patients with at least 1 day of Medicaid coverage during the 1 year before death (yes/no).

ESRD, end-stage renal disease; IQR, interquartile range; ASHD, atherosclerotic heart disease; CHF, congestive heart failure; CVA/ TIA, cerebrovascular accident/transient ischemic attack; PVD, peripheral vascular disease; COPD, chronic obstructive pulmonary disease; GI, gastrointestinal.

groups were less likely to experience trajectory 2 (e.g., blacks, OR 0.76, 95\% CI 0.74-0.78). Patients with Medicaid were more likely to experience trajectory 2 (OR 1.19, 95\% CI 1.16-1.22), and patients in isolated rural towns less likely. In contrast, for any acute medical events, differences in sex, race, and urbanicity generally appeared to be not as strongly related to specific trajectory.

\section{Setting of Death and Associated Factors}

Factors associated with the setting of death are shown in online supplementary Table S3. Withdrawal was associated with substantially lower odds of in-hospital death. In-hospital death was more likely for women and racial minorities, but less likely for patients from more rural settings or with Medicaid coverage. Only at the uppermost range of the disability proxy score were odds of in-hospital death lower than for patients with a score of 0 . Patterns were similar for intensive care unit (ICU) death.

\section{Sensitivity Analyses}

For our main model, we performed several sensitivity analyses. First, we reclassified both withdrawal and nonwithdrawal death such that no deaths were excluded, as described in the online supplementary Methods. Findings, as shown in online supplementary Table S4, were highly similar. Next, given the apparent importance of the trajectory of the disability proxy score described above, we substituted the disability trajectory category for the score itself; overall, findings were similar (online suppl.
Table S5); the disability proxy score trajectory was associated with withdrawal (OR for trajectory 2 vs. 1, 5.41, 95\% CI 5.19-5.64).

\section{Discussion}

In this study, we sought to contrast patients who died after elective hemodialysis withdrawal with those who died of a non-withdrawal cause. We found that women were more likely to withdraw, relative to dying of a nonwithdrawal cause, than men, were generally more likely to experience higher burdens of acute medical events and putative disability prior to death, and were more likely to die in the hospital and in the ICU. Blacks and most other racial minorities (relative to whites) were substantially less likely to withdraw than to die of a non-withdrawal cause, and they appeared to experience lower levels of putative disability prior to death; they were also more likely to die in the hospital and in the ICU. Perhaps paradoxically, patients in the most rural areas were more likely to withdraw despite having the greatest likelihood of favorable end-oflife trajectories for disability and acute medical events. Patients with Medicaid, a marker of worse socioeconomic status, were less likely to withdraw than those without, despite generally less favorable end-of-life trajectories for disability and acute medical events. Remarkably, even dialysis patients aged $>85$ years were no less likely to die in the hospital than patients aged decades younger. Perhaps 
Table 2. Factors associated with death from withdrawal versus death from other causes

\begin{tabular}{|c|c|c|}
\hline Variable & OR (95\% CI) & $p$ value \\
\hline Intercept & $0.02(0.02-0.03)$ & $<0.0001$ \\
\hline \multicolumn{3}{|l|}{ Age, years } \\
\hline $18-44$ & $0.72(0.61-0.85)$ & $<0.0001$ \\
\hline $45-64$ & 1.00 (ref.) & \\
\hline $65-74$ & $1.38(1.30-1.47)$ & $<0.0001$ \\
\hline $75-84$ & $1.82(1.72-1.94)$ & $<0.0001$ \\
\hline$\geq 85$ & $2.41(2.26-2.59)$ & $<0.0001$ \\
\hline \multicolumn{3}{|l|}{ Gender } \\
\hline Female & $1.19(1.15-1.24)$ & $<0.0001$ \\
\hline \multirow{2}{*}{\multicolumn{3}{|c|}{ Race/ethnicity }} \\
\hline & & \\
\hline White & 1.00 (ref.) & \\
\hline Black & $0.42(0.40-0.45)$ & $<0.0001$ \\
\hline Asian & $0.61(0.53-0.70)$ & $<0.0001$ \\
\hline Native Americans & $1.12(0.94-1.33)$ & 0.2105 \\
\hline Other/unknown & $0.78(0.61-0.99)$ & 0.0388 \\
\hline Hispanic & $0.66(0.62-0.71)$ & $<0.0001$ \\
\hline \multicolumn{3}{|l|}{ Dialysis duration, years } \\
\hline$<2$ & $0.96(0.91-1.02)$ & 0.1538 \\
\hline $2-<5$ & 1.00 (ref.) & \\
\hline$\geq 5$ & $1.02(0.98-1.07)$ & 0.3193 \\
\hline \multicolumn{3}{|l|}{ Primary cause of ESRD } \\
\hline Diabetes & 1.00 (ref.) & \\
\hline Hypertension & $0.89(0.84-0.94)$ & $<0.0001$ \\
\hline Glomerulonephritis & $1.13(1.04-1.24)$ & 0.0056 \\
\hline Other cause & $1.09(1.02-1.17)$ & 0.0099 \\
\hline \multicolumn{3}{|l|}{ Institutional stay, days } \\
\hline 0 & 1.00 (ref.) & \\
\hline $1-<10$ & $0.91(0.84-0.99)$ & 0.0272 \\
\hline $10-<25$ & $1.12(1.04-1.21)$ & 0.004 \\
\hline $25-<58$ & $1.10(1.01-1.19)$ & 0.024 \\
\hline$\geq 58$ & $1.04(0.96-1.13)$ & 0.3246 \\
\hline \multicolumn{3}{|l|}{ Urbanicity } \\
\hline Urban & 1.00 (ref.) & \\
\hline Large rural city/town & $1.15(1.09-1.23)$ & $<0.0001$ \\
\hline Small rural town & $1.17(1.08-1.27)$ & $<0.0001$ \\
\hline Isolated small rural town & $1.37(1.25-1.50)$ & $<0.0001$ \\
\hline Missing & $0.59(0.47-0.73)$ & $<0.0001$ \\
\hline \multicolumn{3}{|l|}{ Medicaid coverage } \\
\hline No & 1.00 (ref.) & \\
\hline Yes & $0.90(0.86-0.94)$ & $<0.0001$ \\
\hline \multicolumn{3}{|l|}{ Comorbid conditions } \\
\hline ASHD & $0.86(0.82-0.90)$ & $<0.0001$ \\
\hline CHF & $0.71(0.68-0.75)$ & $<0.0001$ \\
\hline CVA/TIA & $0.94(0.89-0.98)$ & 0.0057 \\
\hline PVD & $1.00(0.96-1.04)$ & 0.9914 \\
\hline Other cardiac disease & $0.84(0.80-0.88)$ & $<0.0001$ \\
\hline COPD & $0.67(0.65-0.70)$ & $<0.0001$ \\
\hline GI bleeding & $1.04(0.98-1.10)$ & 0.2164 \\
\hline Liver disease & $1.02(0.95-1.09)$ & 0.5475 \\
\hline Dysrhythmia & $0.98(0.94-1.02)$ & 0.38 \\
\hline Cancer & $0.88(0.83-0.93)$ & $<0.0001$ \\
\hline Diabetes & $0.84(0.79-0.88)$ & $<0.0001$ \\
\hline \multicolumn{3}{|l|}{ Disability proxy score } \\
\hline$\leq 0$ & 1.00 (ref.) & \\
\hline $1-2$ & $1.68(1.51-1.87)$ & $<0.0001$ \\
\hline $3-4$ & $2.03(1.82-2.26)$ & $<0.0001$ \\
\hline $5-6$ & $2.68(2.39-3.01)$ & $<0.0001$ \\
\hline$\geq 7$ & $31.16(28.40-34.20)$ & $<0.0001$ \\
\hline
\end{tabular}

ESRD, end-stage renal disease; ASHD, atherosclerotic heart disease; CHF, congested heart failure; CVA/TIA, cerebrovascular accident/transient ischemic attack; PVD, peripheral vascular disease; COPD, chronic obstructive pulmonary disease; GI, gastrointestinal. most importantly, worsening disability, at least when ascertained by a claims-based algorithm, appeared to be an important signal associated with elective dialysis withdrawal, even more than medical events themselves.

The phenomenon known as the "illness trajectory" was elucidated over a decade ago [34]. Foundational work was conducted by Kurella et al. [35], who demonstrated that in older patients initiating dialysis, the trajectory of frailty typically worsens over just a few months. This work highlighted the importance of worsening frailty (and, presumably, its proxy, disability) in the months prior to death, a period that represents a key window during which patients might attempt to exert some degree of agency over their lives as health status declines, illnesses become more complex, medical events manifest more acutely, and disability becomes more pronounced.

Previously, we found that disability appeared to be an important factor associated with elective dialysis withdrawal [25]. However, that work contrasted withdrawers with patients who remained alive (i.e., who could have withdrawn, but did not). Left unanswered was whether the milieu of medical events and disability for patients who eventually withdrew differed from that for those who died of another (non-withdrawal) cause. The present work suggests that the decision to withdraw, relative to dying of another cause, may be shaped, at least in part, by changes in putative disability. The disability proxy score increased more sharply for withdrawers prior to death than for non-withdrawers and was associated with elective withdrawal in our model. This was supported by the trajectory analyses, in which the patients who followed the "sicker" disability trajectory were relatively overrepresented by withdrawers with an OR exceeding 5.0.

This finding suggests that clinicians should consider worsening disability when end-of-life care is discussed with dialysis patients. Increasing disability is akin (although not identical) to frailty, which has been shown to be a strong predictor of mortality in the general population [36] and which has been suggested in the general medical literature as a key point of discussion between physicians and their patients [37]. End-of-life care discussions and clarification of care directives are important exercises that can limit unwanted, unnecessary, or futile medical interventions. Our results suggest that consideration of increasing disability may be important in end-oflife care planning.

Our work demonstrates important findings regarding racial differences in the period preceding death. Given recent findings on racial disparities in end-of-life dialysis care [19], we were unsurprised to find that members of 

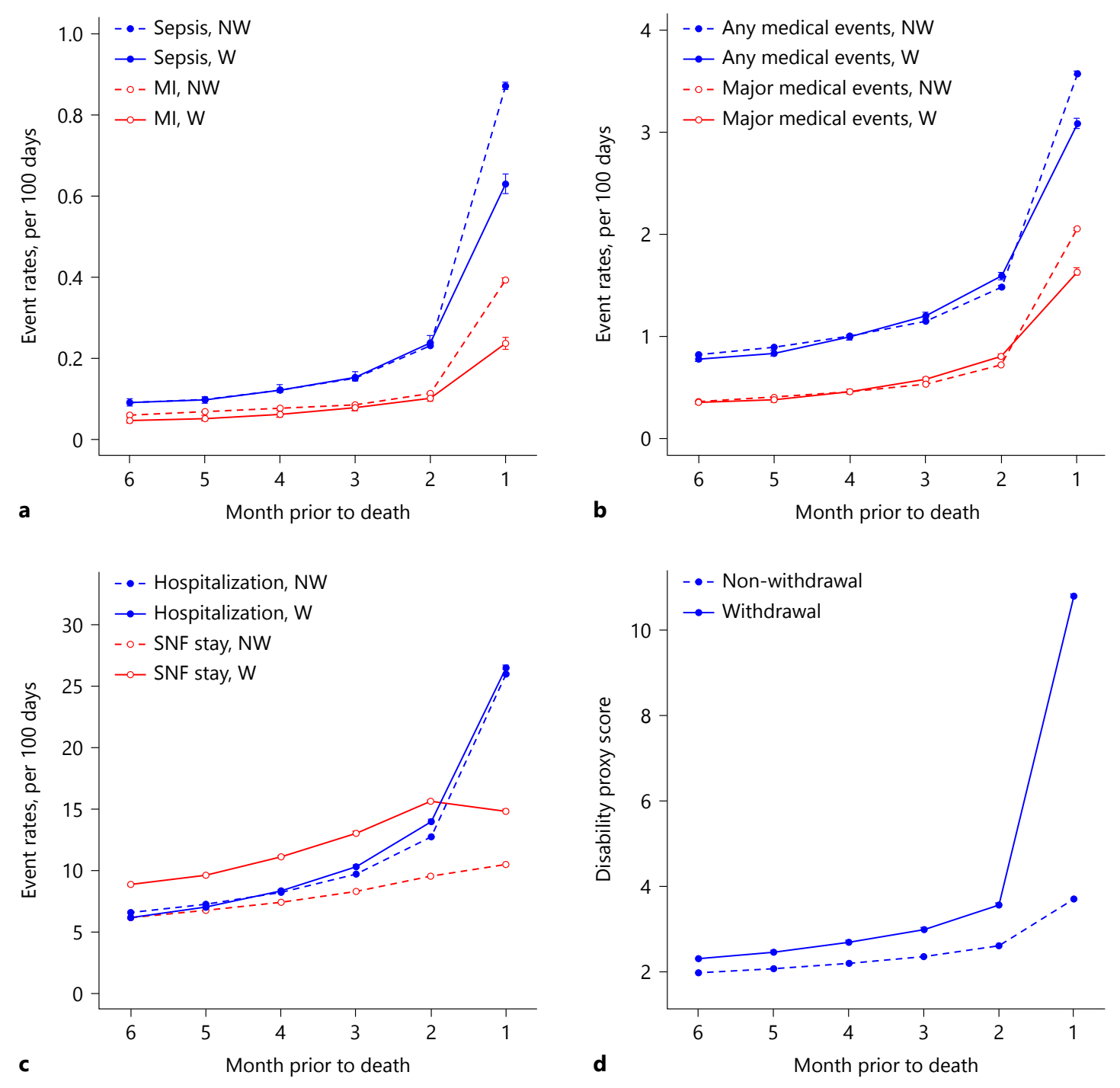

Fig. 1. a-d Rate estimates for clinical events, institutionalization, and disability proxy score over the 6 months preceding dialysis withdrawal. NW, non-withdrawer; W, withdrawer; MI, myocardial infarction; SNF, skilled nursing facility.

racial minorities were generally less likely to electively withdraw than whites. Our results were also concordant with studies using alternative designs $[13,14,26,27]$. Particularly notable, however, was the magnitude of the effect: blacks, for example, were less than half as likely to withdraw as whites. In addition, racial minorities appear to receive more intensive medical care at the end of life; they were more likely than whites to die in the hospital, as also found in a recent study [19], and in the ICU [38]. Members of racial minority groups appeared to have a lower disability burden prior to death, as shown by the trajectory analysis of the disability proxy score. However, this likely only partially explains racial differences in the likelihood of dialysis withdrawal, given that our model of withdrawal adjusted for the disability proxy score (and, in a sensitivity analysis, disability trajectory). Reasons for these differences are uncertain; possibly yet-undefined barriers to withdrawal or to de-escalation of medical care may exist, including the possibility that nephrologists and other providers do not discuss medical de-escalation in the same terms with black or other minority patients relative to whites. 
Table 3. Factors associated with trajectory 2 (representing the "sicker" trajectory) versus trajectory 1 ("healthier") for medical events and the disability proxy score

\begin{tabular}{|c|c|c|c|c|}
\hline \multirow[t]{2}{*}{ Variable } & \multicolumn{2}{|c|}{ Disability proxy score } & \multicolumn{2}{|l|}{ Any medical event } \\
\hline & OR (95\% CI) & $p$ value & OR (95\% CI) & $p$ value \\
\hline Intercept & $0.08(0.07-0.08)$ & $<0.0001$ & $0.26(0.24-0.27)$ & $<0.0001$ \\
\hline \multicolumn{5}{|l|}{ Age, years } \\
\hline $18-44$ & $0.66(0.61-0.70)$ & $<0.0001$ & $1.05(0.99-1.11)$ & 0.078 \\
\hline $45-64$ & 1.00 (ref.) & & 1.00 (ref.) & \\
\hline $65-74$ & $1.38(1.34-1.43)$ & $<0.0001$ & $0.99(0.97-1.02)$ & 0.66 \\
\hline $75-84$ & $1.60(1.55-1.66)$ & $<0.0001$ & $0.89(0.87-0.92)$ & $<0.0001$ \\
\hline$\geq 85$ & $1.77(1.70-1.85)$ & $<0.0001$ & $0.74(0.71-0.77)$ & $<0.0001$ \\
\hline \multicolumn{5}{|l|}{ Gender } \\
\hline Female & $1.32(1.29-1.35)$ & $<0.0001$ & $1.02(1.00-1.05)$ & 0.040 \\
\hline Male & 1.00 (ref.) & & 1.00 (ref.) & \\
\hline \multicolumn{5}{|l|}{ Race/ethnicity } \\
\hline White & 1.00 (ref.) & & 1.00 (ref.) & \\
\hline Black & $0.76(0.74-0.78)$ & $<0.0001$ & $1.12(1.09-1.15)$ & $<0.0001$ \\
\hline Asian & $0.52(0.48-0.57)$ & $<0.0001$ & $0.90(0.84-0.97)$ & 0.0031 \\
\hline Native Americans & $0.60(0.53-0.68)$ & $<0.0001$ & $0.91(0.82-1.00)$ & 0.052 \\
\hline Other/unknown & $0.48(0.42-0.56)$ & $<0.0001$ & $0.86(0.77-0.96)$ & 0.0091 \\
\hline Hispanic & $0.86(0.82-0.89)$ & $<0.0001$ & $1.05(1.01-1.08)$ & $<0.0076$ \\
\hline \multicolumn{5}{|l|}{ Dialysis duration, years } \\
\hline$<2$ & $1.02(0.99-1.05)$ & 0.26 & $1.06(1.03-1.09)$ & $<0.0001$ \\
\hline $2-<5$ & 1.00 (ref.) & & 1.00 (ref.) & \\
\hline$\geq 5$ & $0.94(0.92-0.97)$ & $<0.0001$ & $0.95(0.93-0.97)$ & $<0.0001$ \\
\hline \multicolumn{5}{|l|}{ Primary cause of ESRD } \\
\hline Diabetes & 1.00 (ref.) & & 1.00 (ref.) & \\
\hline Hypertension & $1.01(0.98-1.04)$ & 0.37 & $0.93(0.91-0.96)$ & $<0.0001$ \\
\hline Glomerulonephritis & $1.00(0.95-1.05)$ & 0.96 & $0.91(0.87-0.95)$ & $<0.0001$ \\
\hline Other cause & $1.00(0.96-1.04)$ & 0.96 & $0.87(0.84-0.90)$ & $<0.0001$ \\
\hline \multicolumn{5}{|l|}{ Urbanicity } \\
\hline Urban & 1.00 (ref.) & & 1.00 (ref.) & \\
\hline Large rural city/town & $1.04(1.00-1.08)$ & 0.063 & $0.84(0.82-0.87)$ & $<0.0001$ \\
\hline Small rural town & $0.99(0.94-1.04)$ & 0.68 & $0.81(0.78-0.85)$ & $<0.0001$ \\
\hline Isolated small rural town & $0.89(0.84-0.94)$ & 0.0001 & $0.79(0.75-0.84)$ & $<0.0001$ \\
\hline Missing & $0.57(0.51-0.64)$ & $<0.0001$ & $0.91(0.84-1.00)$ & 0.045 \\
\hline \multicolumn{5}{|l|}{ Medicaid coverage } \\
\hline No & 1.00 (ref.) & & 1.00 (ref.) & \\
\hline Yes & $1.19(1.16-1.22)$ & $<0.0001$ & $1.18(1.16-1.21)$ & $<0.0001$ \\
\hline \multicolumn{5}{|l|}{ Liu comorbidity index } \\
\hline 0 & 1.00 (ref.) & & 1.00 (ref.) & \\
\hline $1-4$ & $2.04(1.93-2.16)$ & $<0.0001$ & $1.59(1.53-1.66)$ & $<0.0001$ \\
\hline $5-7$ & $3.78(3.57-4.01)$ & $<0.0001$ & $2.79(2.66-2.91)$ & $<0.0001$ \\
\hline$\geq 8$ & $6.37(6.03-6.74)$ & $<0.0001$ & $4.95(4.74-5.16)$ & $<0.0001$ \\
\hline
\end{tabular}

ESRD, end-stage renal disease.

Two other potentially novel demographic findings involved the degree of urbanicity/rurality and socioeconomic status. First, patients who lived in the most rural settings were more likely to withdraw, despite having, on average, lower disability proxy scores and more favorable trajectories in the disability proxy score and in acute medical events in the months leading to death. This suggests the possibility that social isolation and/or distance to hemodialysis units may affect the decision to withdraw. While withdrawal may often be the best and most appropriate option for patients, mere distance to larger cities (and, presumably, health-care facilities) does not seem to be an appropriate reason to elect to withdraw. Second, concerning socioeconomic status, Medicaid coverage was 
associated with lower odds of withdrawal, despite Medicaid patients having less favorable trajectories for the disability proxy score and for acute medical events. In the general population, literature on this topic is conflicting; lower socioeconomic status has been associated with both higher intensity of care at the end of life [39] and, paradoxically, increased use of palliative care consultative services [40]. One possibility regarding our finding is that socioeconomic deprivation may represent a barrier preventing patients from exerting autonomy in end-of-life decision making. Regardless of the explanation, questions arise as to whether some rural patients withdraw merely because of isolation from health-care facilities and whether some indigent patients are not demonstrating full agency over their lives by not withdrawing (or by not being appropriately offered elective withdrawal when it would be a viable option for them).

A final notable finding regarded age: the OR for in-hospital death for the most elderly patients (aged $\geq 85$ years) was no different from that for patients aged 18-64 years. Whether elderly patients receiving maintenance dialysis are being appropriately counseled about non-hospitalization in the face of worsening health status and increasing disability is uncertain.

Our study has several important limitations. We studied only Medicare-insured US patients, limiting generalizability. Perhaps most importantly, there is no "gold standard" regarding what constitutes elective withdrawal; however, we attempted to mitigate this by conducting the main analysis using 2 different operational definitions of withdrawal (and non-withdrawal death). We could not model all potential factors associated with elective withdrawal, such as medical literacy and level of family support. Another weakness is that the CMS Death Notification forms are often incomplete or inaccurate in the cause-of-death, use-of-hospice, and elective-withdrawal fields. These forms are therefore imperfect at distinguishing withdrawal from non-withdrawal death, but we employed a careful strategy to attempt to distinguish these fundamentally different types of death. As a further limitation, patterns of withdrawal versus non-withdrawal death may have changed over time, particularly since 2015 (the last year for which data were available for this study). Changes in hemodialysis patient case-mix (e.g., degree of comorbidity and/or disability) could, over time, alter the ratio of withdrawal to non-withdrawal deaths. We cannot rule this out, but no such change occurred in the data over the period we studied. A more likely possibility is that, over time, withdrawal may have become a more socially or medically "acceptable" approach to end- of-life decision making, meaning that future studies should examine trends in elective withdrawal over time. Additionally, our disability score has not been validated. Finally, residual confounding is likely present, potentially obscuring true associations.

In conclusion, elective withdrawal may be characterized less by an acute increase in medical events and more by worsening disability. Discussion of a patient's overall illness trajectory, including the course of disability, might be important in individualizing patient care toward the end of life. The nephrology community should engage in a robust discussion about how the manner and location of death for patients receiving maintenance dialysis might best reflect the interests of patients and society.

\section{Acknowledgments}

The data reported here have been supplied by the USRDS. The interpretation and reporting of these data are the responsibility of the author(s) and in no way should be seen as an official policy or interpretation of the US government.

The authors gratefully acknowledge the helpful insights of Nicholas S. Roetker, PhD, of the Chronic Disease Research Group and thank Chronic Disease Research Group colleagues Anne Shaw for manuscript preparation and Nan Booth, MSW, MPH, ELS, for manuscript editing.

\section{Statement of Ethics}

We received approval from the Human Subjects Research Committee of the Hennepin County Medical Center/Hennepin Healthcare System, Inc. to conduct the study, and a Data Use Agreement was in place between the investigators and the USRDS.

\section{Disclosure Statement}

The authors have no conflicts of interest to declare.

\section{Funding Sources}

This study was funded by NIH (NIDDK) grant number DK104006 to JBW.

\section{Author Contributions}

J.B.W., D.T.G., and J.L. designed the study. H.Y. and J.L. conducted the analysis. J.B.W., H.Y., D.T.G., and J.L. interpreted the data. H.Y. made the figures. J.B.W. drafted the initial manuscript. H.Y., D.T.G., and J.L. revised the manuscript. All authors approved the final version of the manuscript. 


\section{References}

1 Murtagh FE, Cohen LM, Germain MJ. The "no dialysis" option. Adv Chronic Kidney Dis. 2011 Nov;18(6):443-9.

2 Davison SN, Jassal SV. Supportive care: integration of patient-centered kidney care to manage symptoms and geriatric syndromes. Clin J Am Soc Nephrol. 2016 Oct;11(10):1882-91.

3 Morton RL, Kurella Tamura M, Coast J, Davison SN. Supportive care: economic considerations in advanced kidney disease. Clin J Am Soc Nephrol. 2016 Oct;11(10):1915-20.

4 Murtagh FE, Burns A, Moranne O, Morton RL, NaickerS.Supportivecare:comprehensiveconservative care in end-stage kidney disease. Clin J Am Soc Nephrol.2016 Oct;11(10):1909-14.

5 Davison SN, Tupala B, Wasylynuk BA, Siu V, Sinnarajah A, Triscott J. Recommendations for the care of patients receiving conservative kidney management: focus on management of CKD and symptoms. Clin J Am Soc Nephrol. 2019 Apr;14(4):626-34.

6 O'Connor NR, Kumar P. Conservative management of end-stage renal disease without dialysis: a systematic review. J Palliat Med. 2012 Feb;15(2):228-35.

7 Muthalagappan S, Johansson L, Kong WM, Brown EA. Dialysis or conservative care for frail older patients: ethics of shared decisionmaking. Nephrol Dial Transplant. 2013 Nov; 28(11):2717-22.

8 van Biesen W, van de Luijtgaarden MW, Brown EA,MichelJP,vanMunsterBC,JagerKJ,etal.Nephrologists' perceptionsregardingdialysiswithdrawalandpalliativecareinEurope:lessonsfrom a European Renal Best Practice survey. Nephrol DialTransplant.2015Dec;30(12):1951-8.

9 Fung E, Slesnick N, Kurella Tamura M, Schiller B. A survey of views and practice patterns of dialysis medical directors toward end-of-life decision making for patients with end-stage renal disease. Palliat Med. 2016 Jul;30(7):653-60.

10 Couchoud C, Arnaud DB, Lobbedez T, BlanchardS, ChantrelF, Maurizi-Balzan J, etal.; REIN registry. Access to and characteristics of palliative care-related hospitalization in the management of end-stage renal disease patients on renal replacement therapy in France. Nephrology (Carlton). 2017 Aug;22(8):598-608.

11 Lazenby S, Edwards A, Samuriwo R, Riley S, Murray MA, Carson-Stevens A. End-of-life care decisions for haemodialysis patients 'We only tend to have that discussion with them when they start deteriorating'. Health Expect. 2017 Apr;20(2):260-73.

12 Kurella Tamura M, Goldstein MK, Pérez-Stable EJ. Preferences for dialysis withdrawal and engagement in advance care planning within a diverse sample of dialysis patients. Nephrol Dial Transplant. 2010 Jan;25(1):237-42.

13 Chan HW, Clayton PA, McDonald SP, Agar JW, Jose MD. Risk factors for dialysis withdrawal: an analysis of the Australia and New Zealand Dialysis and Transplant (ANZDATA) Registry, 1999-2008. Clin J Am Soc Nephrol. 2012 May;7(5):775-81.
14 Ellwood AD, JassalSV, Suri RS, Clark WF, NaY, Moist LM. Early dialysis initiation and rates and timing of withdrawal from dialysis in Canada. Clin J Am Soc Nephrol. 2013 Feb;8(2):265-70.

15 O'Hare AM, Vig EK, Hebert PL. Initiation of dialysis at higher levels of estimated GFR and subsequent withdrawal. Clin J Am Soc Nephrol. 2013 Feb;8(2):179-81.

16 Aggarwal Y, Baharani J. End-of-life decision making: withdrawing from dialysis: a 12-year retrospective single centre experience from the UK. BMJ Support Palliat Care. 2014 Dec; 4(4):368-76.

17 Couchoud CG, Beuscart JB, Aldigier JC, Brunet PJ, Moranne OP; REIN registry. Development of a risk stratification algorithm to improve patient-centered care and decision making for incident elderly patients with end-stage renal disease. Kidney Int. 2015 Nov;88(5):1178-86.

18 Findlay MD, Donaldson K, Doyle A, Fox JG, Khan I, McDonald J, et al.; Scottish Renal Registry (SRR). Factors influencing withdrawal from dialysis: a national registry study. Nephrol Dial Transplant. 2016 Dec;31(12):2041-8.

19 Foley RN, Sexton DJ, Drawz P, Ishani A, Reule S. Race, ethnicity, and end-of-life care in dialysis patients in the United States. J Am Soc Nephrol. 2018 Sep;29(9):2387-99.

20 Association RP. Shared decision making in the appropriate initiation of and withdrawal from dialysis: clinical practice guideline, Second Edition. [Accessed January 9, 2020]. Available from: https://cdn.ymaws.com/ www.renalmd.org/resource/resmgr/Store/ Shared_Decision_Making_Recom.pdf.

21 Murphy E, Germain MJ, Cairns H, Higginson IJ, Murtagh FE. International variation in classification of dialysis withdrawal: a systematic review. Nephrol Dial Transplant. 2014 Mar;29(3):625-35.

22 Schmidt RJ, Moss AH. Dying on dialysis: the case for a dignified withdrawal. Clin J Am Soc Nephrol. 2014 Jan;9(1):174-80.

23 Hussain JA, Flemming K, Murtagh FE, Johnson MJ. Patient and health care professional decision-making to commence and withdraw from renal dialysis: a systematic review of qualitative research. Clin J Am Soc Nephrol. 2015 Jul;10(7):1201-15.

24 Watanabe Y, Hirakata H, Okada K, Yamamoto H, Tsuruya K, Sakai K, et al.; Japanese Society for Hemodialysis Therapy Guideline Commission of Maintenance Hemodialysis Investigation Subgroup Commission on Withholding and Withdrawal from Dialysis. Proposal for the shared decision-making process regarding initiation and continuation of maintenance hemodialysis. Ther Apher Dial. 2015 Mar;19 Suppl 1:108-17.

25 Wetmore JB, Yan H, Hu Y, Gilbertson DT, Liu J. Factors associated with withdrawal from maintenance dialysis: a case-control analysis. Am J Kidney Dis. 2018 Jun;71(6):831-41.

26 Leggat JE Jr, Bloembergen WE, Levine G, Hulbert-Shearon TE, Port FK. An analysis of risk factors for withdrawal from dialysis before death. J Am Soc Nephrol. 1997 Nov; 8(11):1755-63.

27 Fissell RB, Bragg-Gresham JL, Lopes AA, Cruz JM, Fukuhara S, Asano Y, et al. Factors associated with "do not resuscitate" orders and rates of withdrawal from hemodialysis in the international DOPPS. Kidney Int. 2005 Sep;68(3):1282-8.

28 Wetmore JB, Roetker NS, Gilbertson DT, Liu J. Early withdrawal and non-withdrawal death in the months following hemodialysis initiation: A retrospective cohort analysis. Hemodial Int. 2019 Apr;23(2):261-72.

29 Wetmore JB, Liu J, Wirtz HS, Gilbertson DT, Cooper K, Nieman KM, et al. Geovariation in fracture risk among patients receiving hemodialysis. Clin J Am Soc Nephrol. 2016 Aug; 11(8):1413-21.

30 Nagin DS, Tremblay RE. Analyzing developmental trajectories of distinct but related behaviors: a group-based method. Psychol Methods. 2001 Mar;6(1):18-34.

31 Jones BL, Nagin DS. Advances in groupbased trajectory modeling and an SAS procedure for estimating them. Sociol Methods Res. 2007 May;35(4):542-71.

32 O'Hare AM, Batten A, Burrows NR, Pavkov ME, Taylor L, Gupta I, et al. Trajectories of kidney function decline in the 2 years before initiation of long-term dialysis. Am J Kidney Dis. 2012 Apr;59(4):513-22.

33 Jones BL. Traj: group-based modeling of longitudinal data. 2016. [August 5, 2019]. Available from: https://www andrew $\mathrm{cmu}$ edu/ user/bjones/index htm.

34 Holley JL. Palliative care in end-stage renal disease: illness trajectories, communication, and hospice use. Adv Chronic Kidney Dis. 2007 Oct;14(4):402-8.

35 Kurella Tamura M, Covinsky KE, Chertow GM, Yaffe K, Landefeld CS, McCulloch CE. Functional status of elderly adults before and after initiation of dialysis. N Engl J Med. 2009 Oct;361(16):1539-47.

36 Clegg A, Young J, Iliffe S, Rikkert MO, Rockwood K. Frailty in elderly people. Lancet. 2013 Mar;381(9868):752-62.

37 Cardona-Morrell M, Lewis E, Suman S, HaywoodC,WilliamsM,BrousseauAA, etal.Recognisingolderfrailpatientsneartheendoflife: what next? Eur J Intern Med. 2017 Nov;45:84-90.

38 Wong SP, Kreuter W, O'Hare AM. Treatment intensity at the end of life in older adults receiving long-term dialysis. Arch Intern Med. 2012 Apr;172(8):661-3.

39 Brown CE, Engelberg RA, Sharma R, DowneyL, FaustoJA,SibleyJ,etal.Race/ethnicity,socioeconomic status, and healthcare intensity at the end oflife.JPalliat Med.2018Sep;21(9):1308-16.

40 Ando T, Adegbala O, Uemura T, Akintoye E, Ashraf S, Briasoulis A, et al. Incidence, trends, and predictors of palliative care consultation after aortic valve replacement in the United States. J Palliat Care. 2019 Apr;34(2):111-7. 